\title{
Tristeza, disforia e bem-estar: perspectivas etnográficas sobre a escolarização de Pessoas Trans
}

\author{
ALEF DE OLIVEIRA LIMA \\ UNIVERSIDADE FEDERAL DO RIO GRANDE DO SUL (UFRGS), PORTO ALEGRE (RS), BRASIL. \\ HTTP://ORCID.ORG/OOOO-0002-7390-3679
}

\section{Introdução}

Talvez não seja um grande desafio descrever com o mínimo de acuidade o modo como as Pessoas Trans $^{1}$ são tratadas e acolhidas nos espaços escolares. De certo, basta que se examine rapidamente a produção reflexiva sobre gênero, identidades Trans e diversidade no campo da educação escolar (Santos \& Silva, 2017). O que tenho a oferecer à questão do processo de escolarização de estudantes transgêneros se deveu à minha própria experiência como um docente cisgênero ${ }^{2}$ de Sociologia, em um Coletivo de Educação Popular na cidade de Porto Alegre (RS), chamado TransEnem. Trata-se de uma etnografia que venho desenvolvendo ao longo da pesquisa de doutorado, portanto parte do texto é um fragmento dos argumentos que possivelmente serão utilizados na tese.

Elencar as dificuldades e a solidão causadas por um espaço escolar que despreza a diversidade ou não reconhece a singularidade dos sujeitos não é uma novidade. Mas de que maneira, factualmente, isso ocorre? De que modo subsiste também uma dimensão corporalizada nessa escolarização? Bem, é verdade que se pode recorrer aos clichês, às narrativas-padrão sobre as formas de definir o preconceito

$1 \mathrm{O}$ termo Pessoa Trans escrito com iniciais maiúsculas se justifica por pelo menos duas razões: 1. Política: refere-se a uma escolha de designação que enfatiza o caráter de sujeito/pessoa aos interlocutores(as) da pesquisa; 2. Simbólica: acompanha a opção esboçada pela comunidade Trans em diferentes momentos de seu ativismo, ao enfatizar ou evidenciar sua existência enquanto um fato politicamente inegável. A palavra transgeneridade sintetiza a experiência e a existência de pessoas cujo gênero designado compulsoriamente ao nascer encontra-se em desacordo com sua vivência subjetiva e corporal. O conceito de transgeneridade é usado aqui como termo guarda-chuva para essas diversas existências não hegemônicas de identidade de gênero (Jesus, 2012).

2 Cisgeneridade descreve o indivíduo que, supostamente, se encontra de acordo com o gênero compulsório designado desde o nascimento pelo discurso social vigente. A terminologia 'cis' tem um princípio inicialmente contrastivo para diferenciar com as Pessoas Trans. A palavra foi criada por Donna Lynn Matthews ( $c f$. http://donnas-hideout.org/tg_def.html. Acesso em 13/11/2019). 'Cis' seria aquele ou aquela que, por não ter sua identidade de gênero atacada por diversos saberes e práticas, naturaliza sua posição de gênero. 
a partir do bullying, da violência difusa, física e psicológica às quais as Pessoas Trans são submetidas cotidianamente. Para mim, não foi fácil escutar a minha turma. Quando propus realizar oficinas de pesquisa, a fim de sondar que demandas se traduzem no abandono da vida estudantil, não imaginei a variedade de feições, corporeidades e sentimentos que se inscrevem subjetivamente nessa "vivência evadida".

Com esse termo, "vivência evadida", sintetizo uma série de posicionamentos dentro de uma matriz normativa que se define por gestos, práticas e discursos. Um modo de fazer evadir ou impelir a Pessoa Trans para fora da escola. Sendo então possível compreender a evasão como um último estágio de uma vida estudantil precarizada por certos tipos de microações destinadas, antes, a fazer um movimento de saída da escola na forma de uma sutileza, aparentemente desprovida de intencionalidade ou de sentido social, assim gerando um processo de estigmatização sobre aquele(a) que optou pela evasão dos quadros escolares. Pode-se acrescentar a isso uma verdadeira forma de expulsão compulsória, conforme uma cultura escolar da re/produção da diferença em que o espaço pedagógico se mostra um lugar de fobia/repressão para os/as estudantes Trans (Oliveira Júnior \& Maio, 2016).

Logo, no decorrer desse processo de escuta e problematização junto com a turma, foram tomando forma alguns dos principais aspectos pelos quais a experiência Trans é evocada dentro da escolarização. Entre esses pontos, gostaria de destacar: a tristeza como sentimento-motriz; a disforia na forma de um marcador social transversal (e problemático) das identidades Trans e Travestis; por fim, a sensação de bem-estar quando acompanhada pelo reconhecimento social do gênero escolhido. Porquanto a perspectiva utilizada nesse trabalho esteja orientada por um viés antropológico, a proposta é descrever de que maneira esses pontos são mobilizados e agenciados nas narrativas dos(as) estudantes. Em todo o caso, não viso totalizar a experiência dos interlocutores em ações isoladas, mas sim situá-las nas formulações de uma coletividade que se remetia ao contexto das aulas e oficinas.

Antes, é preciso definir e localizar minimamente o que é o TransEnem e o seu escopo de implementação. O Coletivo nasceu da iniciativa civil de mulheres e homens LGBT e Trans de Porto Alegre que decidiram criar um projeto popular de educação centrado nos temas de gênero e diversidade sexual, que seria também um cursinho pré-vestibular, nos idos de 2015. A ação foi inspirada em outras iniciativas que se (in)surgiam na mesma época, como o PreparaNem, no Rio de Janeiro (RJ), e o TransEnem de Belo Horizonte (MG). De imediato a proposta do Coletivo teve uma adesão organizativa de voluntários, licenciandos e professores formados, interessados na construção de uma mínima estrutura para atuação e recebimento do corpo discente. As aulas ocorriam muitas vezes nos apartamentos e casas dos voluntários. Em 2016, por meio de uma parceria com o Instituto Federal do Rio Grande do Sul (IFRS), o Coletivo TransEnem ganhou uma face institucional enquanto projeto de extensão.

Com a nova interface de atuação, o Coletivo criou um slogan de divulgação por meio das redes sociais, reforçou a equipe de professores voluntários, passou a realizar entrevistas individuais de seleção e a ofertar formações específicas no campo da educação popular e transexualidade. A equipe de organização também optou por formar um grupo psicopedagógico com psicólogos(as), assistentes sociais e pedagogos(as), para a construção de formas de acolhimentos mais profissionais e comprometidas eticamente. Particularmente, conheci o TransEnem em 2018, quando ingressei como docente junto com mais dois professores da disciplina de Sociologia. Lembro-me que, na arguição individual que tivemos, 
foi enfatizado que o tipo de proposta do Coletivo se alinha a uma perspectiva política e pedagógica da diversidade e da diferença como lema educacional e que essa questão era traduzida nas aulas, mais propriamente, dentro do trabalho professoral requerido, em que se nutria um olhar mais amplo sobre as relações de ensino-aprendizagem.

Pelo fato de ser uma atividade voluntária, o Coletivo tem uma considerável rotatividade de pessoas que entram e saem a cada ano. Atualmente, o núcleo duro de iniciadores e fundadores já se encontra complemente modificado. Essa é uma das razões pelas quais aqueles que assim desejam participar das atividades devem passar por uma capacitação específica sobre os valores e a visão social do TransEnem. As atividades e eventos do Coletivo são custeadas por meio de rifas, parcerias com empresários locais do meio $\mathrm{LGBT}^{3}$, brechós colaborativos e outros. O modo de funcionamento do TransEnem é por meio de assembleias gerais (reuniões mensais em que se privilegia a horizontalidade da discussão), em que são decididas pautas, resoluções dos problemas encontrados e novas ações.

No caso dos(as) professores(as), a autonomia é um princípio fundamental para construção da proposta curricular dos conteúdos de cada semestre e das metodologias de ensino. Cada área do conhecimento possui liberdade sobre as formas de esquematizar os critérios de aprendizagem. Obviamente, os conhecimentos e habilidades solicitados nas provas do Exame Nacional do Ensino Médio (ENEM), no Exame Nacional para Certificação de Competências de Jovens e Adultos (ENCCEJA) e nos vestibulares da Universidade Federal do Rio Grande do Sul (UFRGS) fornecem a principal diretriz. Destarte, com a possibilidade de propiciar um campo de prática e formação docente para os licenciandos, o TransEnem preserva uma potencialidade política que é enfatizada em seus posicionamentos e mobilizações, fazendo do Coletivo um cursinho incomum por sua própria identidade social.

Cabe mencionar que, se tratando de um contexto etnográfico no campo de uma educação "fora da escola”, é justamente essa identidade marcada pelas questões de gênero e diversidade sexual que produz uma importante pergunta sobre o sentido político dos modos de escolarização convencionais e populares. Durante a construção dessa etapa de coleta de dados e percepções, foi possível compreender que o processo de "passagem pela escola", no caso de Pessoas Trans, resguardava dimensões corporais, emocionais, políticas e éticas que não estavam restritas a um entendimento estanque sobre o que é escola. O que, em um primeiro olhar, poderia ser definido como algo conflitivo e plural acerca do lugar da experiência escolar em suas vidas.

Nos tópicos que se seguem, procuro oportunizar ao leitor o frame metodológico e ético formado durante a experiência de pesquisa junto com os/as estudantes participantes das oficinas. Além de dedicar as duas últimas seções, em específico, para elaborar de modo mais denso os tensionamentos subjetivos que a transexualidade ${ }^{4}$ atravessa no campo da escolarização. Outrossim, as ideias e análises contidas em cada um dos tópicos do texto visam a mediar uma certa construção argumentativa - dedicada a repensar a experiência escolar como algo potencialmente político, por se tratar da vida e da

3 Lésbicas, Gays, Bissexuais e a população Trans em sua diversidade. Outras escritas também inserem Pessoas Intersexuais, Queers, Assexuais.

4 A palavra Transexualidade é aqui utilizada em consonância com o contexto etnográfico investigado, por esse motivo seu sentido designa-se a partir das falas e depoimentos dos(as) interlocutores(as). Em especial, seu uso é compatível com o conceito de transgeneridade e serve como marcador identitário compartilhado pelos(as) interlocutores(as) da pesquisa. É um termo êmico. 
cidadania de pessoas -, ao mesmo tempo em que se assegura um entendimento mais sensível nos temas retratados pela abordagem etnográfica.

\section{Escolhas éticas e metodológicas: a elaboração e a prática das oficinas de pesquisa}

Para realizar a sondagem sobre a experiência escolar dos(as) estudantes sem cair em uma abordagem invasiva, decidi construir com eles e elas uma atividade que fosse tanto destinada aos objetivos da pesquisa quanto a um espaço dialógico. Na pequena sala, onde pouco mais de nove alunos e alunas se reuniam antes de cada aula, avisava que a participação era livre e que, depois dos conteúdos e exercícios didáticos, teríamos as atividades das oficinas (gravadas e, posteriormente, transcritas). A minha sorte foi que todos(as) os(as) estudantes optaram por participar. Mesmo os(as) discentes mais tímidos(as) ou retraídos(as) queriam expor suas demandas e me faziam refletir em cada oficina sobre formas de tornar a atividade mais crítica e reflexiva.

Realizei a primeira oficina em 9 de maio de 2019. Ela teve um roteiro mínimo: utilizei imagens variadas de salas de aulas pelo mundo e pedia que os/as discentes discutissem o que enxergavam sobre desigualdade, escola e diversidade social. O objetivo era realmente alçar vivências próprias, mas sem fazer que isso se tornasse algo doloroso. A ideia era produzir uma projeção com a variabilidade de fotografias e o que elas representavam. O resultado foi positivo em relação à possibilidade de como entender os significados sociais das desigualdades, ao reparar nas condições físicas de cada sala ou nas vestimentas das pessoas retratadas. Assim, utilizando o projetor, nós íamos observando imagem por imagem. Posteriormente, fazíamos um círculo com as carteiras e eu passava um pote com questionamentos; cada participante retirava um papel e expunha suas considerações.

Na segunda oficina, no dia 16 do mesmo mês, fiz um movimento diferente: ao invés de fazer questões fechadas e restritas, optei por incorporar temas trazidos pelos(as) estudantes na primeira atividade. $\mathrm{O}$ objetivo foi transformar suas colocações em palavras-chave que introduzissem e retroalimentassem as problemáticas que havíamos discutido no dia 9 . Assim, criava-se um fio condutor e também um termômetro de assuntos mais importantes. Problemáticas como terapia hormonal, passabilidade preconceito, evasão, cisgeneridade, disforia e gênero ganharam uma atenção especial, não apenas por serem aspectos muito citados e evocados na construção da experiência escolar dos(as) participantes, mas por permitirem uma aproximação da turma com uma pauta comum. Em resumo: os e as estudantes Trans emergiam de cada oficina buscando um "lugar de fala" (Ribeiro, 2019) sobre sua vivência'.

\footnotetext{
5 Passabilidade descreve a possibilidade de "passar" por situações, espaços e olhares sem ter sua identidade de gênero inconvenientemente questionada ou deslegitimada. Em nota, a experiência de ser passável não se configura como um privilégio ou pode ser tomada como um objetivo de toda e qualquer Pessoa Trans. É uma salvaguarda provisória de constrangimentos.

6 Nesse aspecto, ao me utilizar do conceito de "lugar de fala", gostaria de introduzir um tensionamento sobre a representatividade de um pesquisador cis em tratar de questões relacionadas às Pessoas Trans. Em um primeiro momento, a questão talvez não seja de representatividade e sim referente a um processo de aproximação proporcionado tanto pela vivência da docência com alunos(as) Trans, como pela produção de uma etnografia já mencionada com o ativismo. Logo, o "lugar de fala" a ser atribuído é situado nessas coordenadas. Segundo, é necessário reafirmar o caráter situacional das formas de conhecimento e tal aspecto justifica as origens e circunstâncias sociais de produção dos discursos e epistemologias, sendo, justamente, esses pontos enfatizados por Ribeiro no conceito supracitado.
} 
Esse "lugar de fala" que se define como algo propriamente situacional e político, fruto de uma posicionalidade social que permite aos indivíduos se perceberem em um contexto estrutural de violências, acabou se tornando a matéria-prima da abordagem etnográfica que eu realizava junto com a turma. Fato que me levou a perceber o quanto existia uma visceralidade, um aspecto corporal da presença da identidade e do corpo Trans. Sob esse ponto de vista, me deparei com a discussão da "corporeidade" em Csordas (2013:292) e sua definição:

A expressão "fenomenologia cultural da corporeidade" denota uma tentativa de firmar a compreensão da cultura e do self do ponto de partida dos nossos corpos como estando-no-mundo, e requer o reconhecimento de que os nossos corpos são, ao mesmo tempo, a fonte da existência e o local da experiência. Com efeito, a corporeidade é a nossa condição existencial fundamental, a nossa corporalidade (corporeality ou bodiliness) em relação ao mundo e às outras pessoas. (grifos do autor)

A instrução teórico-metodológica de Csordas passou a configurar uma ponte entre os argumentos antropológicos para se entender a experiência escolar de Pessoas Trans, atravessada por sua "corporeidade" e seus sentidos políticos e emocionais. Dito isso, passei a realizar perguntas mais incisivas que possibilitassem o debate. Grande parte das colocações sobre as questões e as respostas delas por parte dos(as) discentes revelavam significados corporificados como sensação de isolamento, tristeza, falta de concentração e o sentimento de que se está sendo vigiado.

É preciso afirmar que a "corporeidade" argumentada pelo antropólogo estadunidense direcionou algumas compreensões mais enfáticas sobre os enfretamentos culturais, somáticos e subjetivos vivenciados pelo público T na escola. Pois Csordas apresenta a corporeidade como algo aquém da dimensão cultural - apesar de lhe ser constitutiva - e além das dimensões subjetivas - mesmo estas sendo atravessadas pelo social. Dessa forma, o corpo se coloca em tensão nos processos sociais. No caso deste artigo, isso se verifica na própria escolarização, na medida em que as repressões normativas se inscrevem no espaço corporal assimetricamente entre os sujeitos cis e Trans.

$\mathrm{Na}$ última atividade, a lógica de retroalimentação pelas palavras-chave foi mantida, objetivando que os(as) estudantes se dessem conta de que sua experiência na escola era situada a partir de diferentes posições, mesmo nos aspectos corporais e emocionais, como enfatizados na ideia de "corporeidade". Em círculo, com a mesma dinâmica, os depoimentos iam sendo compostos e as falas começaram a ser intercaladas com as intervenções dos(as) colegas e com os meus questionamentos, trazendo uma espécie de repositório de informações e vivências, que tornava a atividade muito mais ampla e reflexiva. Assuntos como inserção no mercado de trabalho, relacionamentos, tabus, religiosidade e conservadorismo tomavam forma no decorrer do tempo de fala. Todas as oficinas foram gravadas, por meio de um aplicativo de registro de som em um celular, com anuência dos(as) participantes-discentes e, posteriormente, todas foram transcritas.

Gostaria de reforçar algo relevante: minhas implicações e considerações traçadas neste texto não partem de uma vivência pessoal ou nenhuma experiência semelhante, pois, como mencionado, não sou uma Pessoa Trans. Os relatos e sua densidade empírica ficaram a cargo do corpo discente e isso justifi- 
cou a imersão etnográfica que realizei. Então, é preciso deixar claro que o presente artigo não visa a falar por algo ou alguém; trata-se, isto sim, de retratar uma realidade com o intuito de entender meandros sutis, talvez ignorados propositadamente.

\section{Tristeza, disforia e bem-estar: corpos que sentem e algumas cenas etnográficas}

Durante as observações da oficina de número 3, em especial, tomei nota de algumas falas espontâneas, que iam facilmente se transformando em depoimentos complexos com fortes raízes de descontentamento e tristeza acerca da escola. Em uma delas, um dos alunos, Téo ${ }^{7}$, um jovem de 20 anos, que se reconhece como não binário (isto é, não se coloca como sendo definido pelas imagens de gênero de homem e mulher convencionais) e prefere ser tratado no masculino, confidencia à turma seu sentimento em relação à sua última passagem pela escola:

Para continuar esse papo, vou falar da experiência da minha escola. A maior parte das escolas ou, pelo menos, a escola que eu frequentei antes de vir para o TransEnem, nenhum dos professores de lá, tinha conhecimento sobre identidade de gênero, ninguém sabia o que era isso. E o único trabalho escolar que eu vi sobre esse tema, pegou o tema e falou sobre sexualidade. Tipo, são coisas diferentes. Enfim, os professores, a escola, eles não sabem e nem estão preparados. Então quando tem uma pessoa Trans na escola ela fica jogada no canto. As pessoas não têm discussão sobre gênero em alguns lugares. E também não tem nenhuma mobilização dos professores e alunos para falar sobre isso. $\mathrm{Na}$ escola onde a gente estudava [ele e Fábio, seu colega mais próximo] só teve por causa da gente. Porque nós não erámos pessoas cis e queríamos reconhecimento. Tivemos que falar sobre, porque não dava mais, sabe? E eu saí, eu não terminei o Ensino Médio, eu não consegui voltar para a escola, para esse lugar exatamente por isso. Então eu acho que a falta de preparo só piora ainda mais a situação para as Pessoas Trans. Por que eu sei que não é todo mundo que vai conseguir levantar, ter a coragem de ir e levantar e falar: olha eu sou Trans e vou explicar para vocês o que é ser Trans, na frente de uma sala, então para as pessoas olharem para ela e falarem: "Como eu fico com isso?”. Para eles não importa, quando se trata da nossa vida. Eu sei que é uma coisa muito complicada e depender da Pessoa Trans para trazer isso para o ambiente escolar é algo muito pesado. (Téo, 20 anos, não binário. Oficina 3, 23/05/2019)

Talvez as requisições que Téo parece reivindicar não estejam apenas relacionadas ao se falar sobre identidade de gênero nas escolas, mas à ausência de um acolhimento da temática de modo sério e comprometido, por parte da comunidade como um todo. Quando expunha sua perspectiva, Téo parecia cabisbaixo e imerso em seus próprios pensamentos, refletindo sobre a melhor maneira de falar sem ser tomado como alguém agressivo. Uma marca que, segundo ele, o levou a desistir de passar mais tempo na escola convencional e optar pelo TransEnem. Fabio, 19 anos, homem Trans, complementa as respostas, afirmando que tudo pode ser resumido em “uma sensação de isolamento e solidão".

7 Para resguardar o direito à não identificação dos(as) discentes, todos os nomes utilizados aqui são fictícios. 
Tais ideias me fizeram refletir que as emoções ou, particularmente, o discurso emocional não fornece informações vazias sobre os estados sentimentais. A exemplo do que as antropólogas Lutz e Abu-Lughod (1990) admitem, a partir de contribuiçóes foucaultianas, as emoções estão sempre imbuídas de "micropolíticas" 8 . Portanto, ensejadas entre formas de poder, dominação e resistência. O aspecto afetivo a que Fabio e Téo remetiam não podia ser subsumido de uma intricada relação sobre a qual a normalização escolar manifestava o disciplinamento dos corpos e das sexualidades. Esse ponto ganhou outra repercussão dentro da atividade: não apenas a experiência escolar e seus filtros afetivos, mas, também, o sentido da norma que a escola os fazia viver. O que ocorre é uma relação dual entre a exclusão e a permanência: ser invisibilizado e sacrificar uma possível relação de positividade para com sua escolarização ou nutrir um sentimento de estresse e estabelecer um ponto de conflitualidade com a escola. Logo, os sentimentos, essas "micropolíticas", que arrogam e atravessam as relações sociais com a instituição de ensino, operam também na forma de ressentimento e negação.

Fabio se sente implicado pelas palavras dos colegas que, no decorrer da oficina, estavam se mostrando interessados em partilhar suas vivências. Acabou percebendo, quiçá pelas palavras de Téo, que o ambiente escolar para as Pessoas Trans é hostil e pontuou da seguinte maneira:

\begin{abstract}
Porque tu não tens aceitação, nem segurança, nem paciência. Não só por parte dos professores ou dos colegas, mas por parte de toda a escola. Então se torna um ambiente que te trata completamente mal e você para de pensar no teu futuro e pensa só naquele momento porque está sendo muito ruim. Você passa por uma coisa que não consegue lidar. É como se você estivesse passando por um túnel e que por mais que ande, ande nunca encontra a luz no finalzinho do túnel. Como se estivesse andando em um caminho completamente escuro e Pessoas Trans costumam ter menos que um amigo na escola e isso diz muito desse 'como'. Se você está em um ambiente em que tu és completamente rejeitada ou rejeitado, você fica abatido e não consegue continuar. (Fabio, 20 anos, homem Trans. Oficina 3, 23/05/2019).
\end{abstract}

As falas contêm um certo posicionamento sobre seus próprios processos de ruptura com a escola. Mantendo, inclusive, uma chave de análise importante que não se encontra situada apenas na hostilidade do espaço escolar e, sim, alinhada com o impacto do futuro de ter sua escolarização interrompida. Parte desse argumento merece ser vista em conjunto com os fatores de renda, bem como as possibilidades de trabalho e emprego a que as Pessoas Trans têm acesso ao longo da vida (Souza \& Bernardo, 2014). Entretanto, o marcador desse conflito escola versus sujeito perpassa a construção da própria identidade Trans. Fato que fica mais potente conforme se discute dentro das oficinas a questão da disforia e as identidades de gênero.

Segundo o Manual Diagnóstico e Estatístico de Transtornos Mentais (DSM-5), publicado pela American Psychiatric Association (2014:451), a disforia de gênero designa-se "como termo descritivo geral, refere-se ao descontentamento afetivo/cognitivo de um indivíduo com o gênero designado,

$8 \mathrm{Na}$ obra citada, as autoras não fazem uma divisão estrita entre sentimento e emoção. Porém, para ambas, as emoções podem ser compelidas enquanto estados corporais-mentais mais efusivos e os sentimentos se traduzem por uma relação de preeminência temporalmente mais longa. Logo, a distinção entre emoção e sentimento estaria colocada na ênfase de uma temporalidade na vivência individual e social. 
embora seja definida mais especificamente quando utilizada como categoria diagnóstica". Para os fins deste artigo, essa acepção é insuficiente, na medida em que não engloba de maneira ampla a experiência Trans enquanto um campo de constituição subjetiva, tampouco consegue sintetizar as dimensões ontológicas e éticas que a identidade Trans é capaz de produzir. Mas a escolha do termo se justifica pelo seu sentido êmico, pois serve como tropos de referência aos(às) discentes e demonstra uma certa "psicologização" de suas vivências e discursos ${ }^{10}$.

Parte do público que participa do TransEnem advém de lugares em vulnerabilidade econômica e também de regiões mais periféricas de Porto Alegre, até de cidades próximas, como Alvorada e Canoas. Em sua maioria, eles e elas têm acesso ao Coletivo por meio de suas redes sociais. Algumas poucas tiveram condições de iniciar sua terapia hormonal e seu processo de transição de gênero com ajuda de um profissional de Psicologia. Porém, aqueles que conseguiam, seja pelo Sistema Único de Saúde (SUS), seja pela rede particular, clínicas populares ou serviços de atendimento fornecidos pelas universidades federais, tinham o discurso psicológico em grande conta. Assim, suas falas sobre a disforia, como foi o caso de Cintia e Laura, evocadas desde um depoimento sobre o que os(as) estudantes consideravam um marcador de uma identidade Trans, vinham acompanhadas com um tom psicológico de indagações, muitas vezes focadas no indivíduo.

Laura, uma das alunas Trans que mais se mostrou envolvida na discussão, apontou uma questão interessante sobre como ela percebia a disforia:

Acho que é muito difícil tirar da cabeça esse padrão de corpo de homem e corpo de mulher. A gente querendo ou não é diferente. Biologicamente somos diferentes. $\mathrm{E}$ a gente tem na nossa cabeça que o homem tem o pinto e a mulher vagina. Então eu acho que a disforia nos pega muito por causa disso. Porque mesmo se desconstruindo tanto é uma coisa assim que nasceu com a gente, é toda uma construção diferente. Por exemplo, roupa, saia qualquer um pode usar, mas o corpo de homem vai ser sempre o corpo do homem e corpo de mulher, sempre corpo de mulher. É uma coisa desde o início do tempo. O sexo do ser humano é uma coisa resistente. Então a disforia acaba nos pegando por causa disso. (Laura, mulher Trans, 20 anos. Oficina 3, 23/05/2019, grifo meu)

A estratégia de entendimento que é mencionada em seu comentário merece uma averiguação criteriosa. Afinal, ela parece "naturalizar" a concepção de gênero sem perceber, ao afirmar que a marcação biológica (seja ela fisiológica ou cromossômica) condiciona a percepção dos ideais de masculino e feminino. Não é de todo equivocado o raciocínio; talvez, a preocupação esteja relacionada à necessidade de perscrutar uma percepção social predominante sobre os papéis sociais. Assim, quando Laura menciona “o sexo do ser humano é uma coisa resistente”, ela está apontando tensões de gênero e

9 Atualmente, a menção a disforia de gênero se encontra retirada do DSM-5 em sua versão mais recente e substituída por “Transtorno de Identidade de gênero”. Em 2018, a Organização Mundial de Saúde retirou a “transexualidade” da Classificação Internacional de Doenças.

10 A menção apresentada aqui a uma ideia de psicologização se deve ao modo e ao conteúdo das reflexões trazidas pelos(as) interlocutores(as). Parece-me que o discurso psicológico, por suas características de saber-poder ou mesmo sua propagação nas diferentes frentes sociais e recortes populacionais designou-se na forma de importante espaço informativo e formativo para distintos segmentos da população Trans no Brasil. Sobre um conceito de "biossocialidade”, útil a tal reflexão e que percorre parte de um debate contemporâneo dentro da Antropologia do Corpo e da Saúde, conferir o dossiê: Bioidentidades, Biossocialidades e Espaços Sociais. Vivência: Revista de Antropologia, (1) 41, publicado em 2013. 
sexualidade que não podem ser reduzidas às discussões trazidas por padrões de gênero do Ocidente ou das sociedades ocidentalizadas.

A antropóloga britânica Strathern (2014) argumenta que o gênero - na forma de constructo social - se refere explicitamente aos diferentes mecanismos de corporalização das relações sociais. Logo, em seu trabalho etnográfico com os povos melanésios, o gênero é acompanhado de relações sociais, materialmente ambivalentes entre corpos, artefatos, sexos e memórias. Nesse ponto, para aprofundar essa visão trazida por Strathern, que complexifica as relações generificadas, vale a pena recorrer às falas de Cintia, uma mulher Trans de 35 anos, que veio do interior do Rio Grande do Sul, e as colocações de Alinne, uma mulher lésbica de 30 anos, que prefere ser tratada no masculino, sobre seus respectivos processos de reconhecimento da disforia e da sexualidade:

Eu vejo muito a questão da disforia como algo que confirma o gênero, é como se, pelo fato de ter a disforia, logo eu sou Trans. O que às vezes não é algo completamente real. Falar que não sente isso não é Trans. Como ela é um cara Trans e não odeia seus seios isso não faz sentido. Hum.... Meu corpo é errado, eu não estou em um corpo certo. Sendo que não é um corpo errado, ele é só um corpo, do seu jeitinho, do seu caminho, éo seu corpo, ele não é errado. É algo que é cobrado muito forte dentro da comunidade Trans e querendo ou não quando a gente se insere e tenta se encontrar nessa comunidade. Nós nos deparamos com esse tipo de coisa. Então eu acho que mesmo de forma indireta isso está sempre ali. (Cintia, mulher Trans, 35 anos. Oficina 3, 23/05/2019).

Então concordo com o que ela falou, ela tem um pouco mais de vivência. Desde que eu me conheço por gente sempre me identifiquei mais com o gênero masculino, com as atividades "masculinas". Minha família, minha mãe sempre foi de boa. Eu me vesti de roupa de menino minha adolescência toda. Naquela época eu me identificaria como Trans, mas eu não sei, eu tenho me questionado em relação a isso, porque cada um tem sua individualidade. Mas eu vejo que hoje em dia está muito forte $[s i c]$ as identificações como Pessoas Trans, com toda a questão do desconforto com o próprio corpo, já querem mudar, iniciar a hormonização, fazer mutilações. Talvez, se eu fosse adolescente e tivesse seguido esse caminho, hoje estaria arrependido, com o tempo fui vendo que eu não queria fazer isso (terapia hormonal, mastectomia masculinizadora). (Alinne, mulher Lésbica, 31 anos, Oficina 3, 23/05/2019).

Ambos os depoimentos deixavam em congruência o modo com que a disforia é identificada enquanto forma de demarcar a inclusão/exclusão de um sujeito no rol da categoria da identidade Trans. Esses apontamentos parecem argumentar sobre a construção de relações de identificação entre Pessoas Trans e sua experiência social no mundo, podendo ser remetidos às controversas formalizações que as lutas identitárias se mostram capazes de conter. Sobretudo, como afirma o filósofo anglo-ganês Appiah (2019:43):

o fato conhecido de que nossas identidades são múltiplas e podem interagir umas com as outras de maneiras complexas não é incompatível com a capacidade de fornecer uma breve explicação sobre o que consiste, conceitualmente, qualquer identidade: em termos gerais, mostram como uma 
rotulação e ideias são aplicadas, o que implica uma série de regras sobre como as pessoas designadas para esses rótulos devem se comportar e de como devem ser tratadas (tradução minha, grifos meus).

A problemática da disforia enquanto marcador de uma rede de identificação entre sujeitos Trans contém uma poderosa forma de "performatividade" (Butler, 2003) das relações de gênero. Principalmente quando se percebe, pelas colocações vistas até aqui, que a disforia fornece um campo afirmativo de reconhecimento social. Essa identidade Trans produzida e tensionada por esse aspecto se traduz também em uma cobrança íntima por um bem-estar corporal e político. A questão, a rigor, de modo ainda um pouco superficial, seria: de que modo estabelecer uma identidade Trans e fazer, assim, parte de um grupo social? A luta social não aparece como um obstáculo ao vislumbre de pertencimento, mas uma perspectiva a ser integrada a outra matriz de identidade, agora não pautada pelo lastro da anatomia heteronormativa.

Em suma, existe um complexo conjunto de fatores que carecem de atenção. Um deles, sobre a requisição desse "bem-estar de si" que os/as discentes querem almejar, coloca a disforia em uma outra coordenada. Em uma das aulas, Fábio afirmou, em tom de alívio, que conseguiu usar um vestido e se sentiu bem. Perguntei para ele por que aquilo foi importante. Ele me respondeu sorrindo: "Eu posso me sentir bem com meu gênero em qualquer coisa que eu esteja vestido". Dessa maneira, construir uma identidade Trans é acompanhado pela possibilidade de atravessar a disforia e se reconstruir como sujeito de um outro gênero, independente de marcadores estéticos, sociais ou biológicos.

O "bem-estar de si", que foi mencionado, pode remeter-se às "tecnologias do eu" de Foucault (2001), em que pese a produção de formas éticas de entendimento sobre seus graus subjetivos, interesses e desejos ou nas formulações de vivências marcadas por uma postura de "indisciplina” e resistência aos poderes coercitivos. Quer dizer, sentir-se bem perpassa o reconhecimento do gênero, seu retrato social e sua implicação ontológica na vida de um sujeito, tanto uma matriz de identidade quanto uma performance possível de reencontro com novas maneiras de se perceber como uma pessoa dotada de liberdade, condicionada, mas livre em alguma medida. Algo que se refere àquilo que o filósofo Hacking (2002) denominou de "ontologia histórica”, nesse caso em relação aos papéis de gênero compulsórios, envolvendo conjuntamente a construção de reconhecimentos políticos e éticos sobre suas próprias demandas de identidade, perante a necessidade de autodesconstrução ${ }^{11}$.

A questão que perpassa a relação entre a disforia como um marcador e a experiência escolar em sua complexidade não está pautada por uma causalidade. Trata-se de entender a escola enquanto uma instituição imersa em discursos e práticas pautados em valores hegemônicos. Por vezes dificultando a interação e o acolhimento com demandas de identificação que não são claramente correspondidas, pois é justamente no chão escolar que a corporeidade, identidades, interrelações, medos, alegrias e ansiedades são inscritas em vivências e sentimentos. No palco da escola, em sua dimensão de superfície pública, assumir uma identidade de gênero não padrão reflete-se por uma contestação das representa-

11 Hacking (2002) define a "ontologia histórica", de clara influência da abordagem de Michel Foucault, como um princípio discursivo em que se cria, ou se refaz, modos de ser e fazer, em razão de uma matriz que perfaz e inventa o que definimos enquanto realidade. Com essa definição em mãos, argumento que o gênero se caracteriza também enquanto uma ontologia historicamente situada. Dessa maneira, quando trato desses papéis compulsórios abordados pelos interlocutores em suas vivências, dou proeminência a esses aspectos discursivos e sociais a que Hacking alude em sua conceituação. 
ções de gênero presentes no espaço pedagógico (Lopes, 2001). É sobre essa contestação, nem sempre proposital, que a diferença se torna uma desigualdade.

\section{Escolarização e subjetividade: políticas emocionais de resistência}

Se até o presente momento a experiência Trans no campo escolar é atravessada por uma violência difusa e gera, segundo os argumentos expostos pela turma, um afastamento da conclusão do ciclo da Educação Básica, é possível imaginar novas maneiras de "passar pela escola"12 ? Com certa apreensão no que diz respeito à possibilidade de reinventar a normatividade pedagógica, pode-se propor escolarizações como a exemplificada e oferecida pelo TransEnem (RS), em que as identidades Trans são vislumbradas como marcadores educacionais. Dessa forma, verifica-se uma perspectiva política de acessibilidade de direitos e cidadania, mesmo na Educação Popular.

Incorre-se que os limites da experiência escolar talvez não sejam dimensões estáveis ou suficientemente "modeladas". O compartilhamento de conversas e discussões com os/as estudantes me leva a pensar as potencialidades e vulnerabilidades subjetivadas no decorrer de seus processos formativos. Uma dessas potencialidades é a necessária reinvindicação de uma forte participação sobre as políticas pessoais (íntimas) e de como esse aspecto é transformado na aprendizagem política de uma identidade engajada. Fazendo com que as identidades Trans estejam implicadas no campo de uma luta social que atravessa a mera identidade per se. Ao perspectivar a relação escola e sujeito, marcada por uma singularidade - que, em tese, não deveria impossibilitar o acesso a um direito positivado e juridicamente assegurado -, ocorre uma compreensão mais ampla sobre as políticas educacionais em seu escopo de ação.

O termo "subjetividade", ao qual me refiro no texto, remete mais precisamente a "uma certa forma cultural, mas também uma maneira de habitar tal forma, a qual é reflexiva e ansiosa, em relação às possibilidades das próprias falhas de cada um" (Ortner, 2007:387) ${ }^{13}$. Posto isso, os aspectos que impactam a escolarização de Pessoas Transgêneros erguem uma problemática ética ao campo da educação, no sentido de remarcar as diferenças nos discursos pedagógicos. Do outro lado, o modo de subjetivar essas consequências torna a experiência escolar um fato doloroso e, por vezes, ameaçador, quando o acesso é esquecido como princípio fundamental para possibilitar um reconhecimento qualificado das realidades sociais e existenciais do corpo discente, o que pode ser feito a partir de diferentes recortes: étnico/racial; gênero; deficiência; etc.

12 É importante destacar que o recorte etnográfico do artigo não pretende totalizar as possíveis e variáveis causações do afastamento das Pessoas Trans do espaço institucional da escola, mas seguir com as impressões destacadas pelos interlocutores(as). A respeito de outras interfaces que explicitam os afastamentos e desistências do público T da escola, vale a pena conferir a obra de Cantelli et al. (2019).

13 Não há um consenso estrutural a respeito do conceito de subjetividade em Antropologia, razão pela qual as diferentes noções enfatizam aspectos como tempo, individualidade, agência, resistência, sujeição, poder, cultura, história, memória, trajetos sociais, etc. A definição de Ortner se aproximou mais teoricamente daquilo a que o material empírico do Coletivo aludia, em um olhar mais incisivo. No entanto, deixo em evidência que o conceito de subjetividade trabalhado pelos antropólogos Biehl, Good e Kleinman (2007) é digno de nota por analisar a dimensão subjetiva enquanto espaço de reflexividade, moralidade, cognição, bem como construção de singularidades e idiossincrasias dos sujeitos, sem cair em um culturalismo ingênuo. Logo, a subjetividade também designa os modos com que os sujeitos se engajam na produção de suas particularidades no mundo. 
A escolha lógica e a determinação de continuar a ter uma vida estudantil requer que se considere a construção de políticas corporais e emocionais de resistência que garantam algum tipo de apoio social e moral. Acerca dessas políticas, pessoais e morais, Alinne (já mencionada antes), afirma:

Eu lutei e completei todos os meus estudos. Na época que me formei, que já faz bastante tempo que me formei, sofria bastante preconceito, principalmente pelas minhas vestimentas de menino. Ouvia piadinhas, essas coisas todas. Eu não dava muita bola, porque eu tinha o amparo da minha mãe. Ela sempre foi minha amiga de conversar. Eu me relacionava bem com as pessoas, antes era mais comunicativa, hoje sou mais tranquila e calma. Mas, é sempre um incômodo, você está andando na rua e alguém que você nem conhece vem te zoar. (Alinne, mulher Lésbica, 31 anos. Oficina 2, 16/05/2019).

O argumento de uma mudança subjetiva - a opção por elaborar um filtro de relacionamentos mais estrito e hermético - pode parecer como uma simples reação a alguns tipos de violências vivenciadas na escola. Mas, também, pode conter uma inclinação mais relevante enquanto algo que abala a produção de relações sociais e afeta, nesse caso, a percepção geral dos sujeitos sobre sua personalidade. O que acaba gerando carapaças simbólicas e formas de autossabotagem, atreladas, isto sim, a uma estrutura social que produz sofrimento. Portanto, essas políticas de resistência, nos termos daquilo que resiste à norma (mesmo se pensando à margem e/ou dentro dela), funcionam no interior de reações e entendimentos imersos em vórtices emocionais, que são perpassados por uma morfologia da violência de gênero.

A dificuldade de entrelaçar a escolarização e a subjetividade na forma de uma experiência que contém e é entrecruzada por dimensões corporais, éticas e políticas tem relação com a visão burocratizada sobre o que, de fato, a escola pode representar na vida individual e coletiva. Dentro da turma e conforme pude acompanhar seus desvelos, amarguras sobre professores, colegas, ternura com amigos e familiares que deram amparo emocional e incentivo educacional, foi possível compreender o jogo de interpelação (metafórica) que a transexualidade coloca para a educação escolar, como se inquirisse: no que essa minha singularidade te afeta? Existem algumas questões que se mostram insustentáveis para a norma, na medida em que revelam a gramática de sua arbitrariedade.

\section{Consideraçôes finais}

Procurei demonstrar nesse artigo que as tensões colocadas entre os sujeitos Trans e sua escolarização se deve, em parte, à construção de um olhar normativo da escola em relação a suas demandas e singularidades. O que não deixa de extravasar nas maneiras pelas quais a normatização é reificada tacitamente nas formas de resistência resenhadas ao longo do texto. Por outro lado, tal internalização acaba gerando outras potencialidades, no que diz respeito à produção de identidades socialmente engajadas no campo de lutas políticas e simbólicas, em que o gênero aparece como marcador educacional, precisamente, na acessibilidade ao direito à educação. De todo modo, também evidenciei que as particularidades de Pessoas Trans atreladas à escola e à conclusão do Ensino Básico se mantêm conectadas 
com dimensões emocionais e corporais, gerando, dentre outros aspectos, formas de subjetivação e resistência diversos.

O texto visou a proporcionar ao leitor um recorte da minha experiência como um docente cis em meio a estudantes Trans. Com efeito, a sensação de desnaturalização vem acompanhada por um devir de afetação. Ao me aproximar de questões antes ignoradas, que talvez não fossem significativas para mim ou dentro do meu próprio trabalho pedagógico, pude perspectivar etnograficamente as vulnerabilidades das transexualidades na escola. Essa possibilidade de significação se deveu à minha participação no TransEnem, pois o Coletivo, no seu escopo político, acaba potencializando aquilo que a antropóloga francesa Favret-Saada (2005:160) define sobre "ser afetado":

Como se vê, quando um etnógrafo aceita ser afetado, isso não implica identificar-se com o ponto de vista nativo, nem se aproveitar da experiência de campo para exercitar seu narcisismo. Aceitar ser afetado supõe, todavia, que se assuma o risco de ver seu projeto de conhecimento se desfazer. Pois se o projeto de conhecimento for onipresente, não acontece nada. Mas se acontece alguma coisa e se o projeto de conhecimento não se perde em meio a uma aventura, então uma etnografia é possível (grifos meus).

É preciso ultrapassar a concepção de escolarização como algo meramente instrutivo, propondo justamente uma problematização sobre os aspectos mais escamoteados, no interior de uma análise mais simplista sobre o impacto/significado da escola para outra gama de sujeitos. Assim, isso pressupõe incluir as dimensões de corporeidade, subjetividade e eticidade que mobilizam conflitos, problemáticas e eventuais soluções. Essas considerações, retiradas do convívio e da escuta com estudantes Trans, balizam a necessidade de compreender a passagem pela escola enquanto uma experiência significativamente social, que se traduz em um debate sobre a reivindicação por existência e visibilidade - portanto, uma experiência que é acionada pela chave do enfrentamento ao apagamento social de suas questões e a exigência do reconhecimento de sua cidadania.

No estrito senso, a experiência etnográfica de relatar e se engajar nas vidas do alunado - ao ater-se, atenciosamente, em seus pedidos e lutas - produz um incerto sentimento de necessidade social. Explico: ao pensar as dificuldades impostas a alguém por sua identidade de gênero e os efeitos na vida estudantil (e emocional) que isso acarreta, não consigo deixar de me colocar em uma posição angustiada, pois a experiência escolar aparece conectada a um processo de estigmatização. É nesse sentido que este artigo descreve as tensões que perpassam a vivência escolar de Pessoas Trans. Diga-se ainda que essa tensão se desdobra em formas sutis de sofrimento social e psíquico.

Para finalizar, lanço mão de uma última e importante inspiração, formulada pela cientista política britânica Phillips (2001), no que concerne à junção entre uma "política de ideias" e uma "política de presença" ${ }^{14}$. Segundo a autora, essas duas formas de debate sobre representatividade social contemporânea não se anulam. Possivelmente, vale pensar que a escolarização como política educacional serviria

14 As "políticas de ideias e de presença" fazem uma alusão aos embates contemporâneos a respeito da representatividade dos espaços de poder. Para Phillips, isso coloca uma questão sobre o quanto a presença de mulheres e outros sujeitos de minorias políticas realmente produz um efeito de ação nos espaços de execução de políticas governamentais, nos diversos âmbitos. Logo, a autora repensa a possibilidade dos ideais e valores estarem para além da presença, na tentativa de fazer valer uma efetividade social mais ampla. 
enquanto um potencial laboratório para a mescla desses dois tipos de ideários, pela razão de produzir a diferença além da ideia e a presença, corporal e politicamente falando, na forma de um fato inexorável. A escola, igualmente, atravessa essa oportunidade de representação e diálogo, pois, a rigor, existiu, mesmo que sutilmente, nos depoimentos analisados, uma fala compassiva por inclusão e acolhimento.

Alef de Oliveira Lima é mestre em Antropologia Social pela Universidade Federal do Rio Grande do Sul (UFRGS) e doutorando na mesma instituição. Bolsista de pós-graduação pelo CNPq.

\section{REFERÊNCIAS}

Abu-Lughod, L. \& Lutz, C. (1990). Language and the Politics of Emotion. New York: Cambridge University Press.

American Psychiatry Association. (2014). Manual Diagnóstico e Estatístico de Transtornos Mentais. $5^{\text {a }}$ ed. Porto Alegre: Artmed.

Appiah, K. A. (2019). Las mentiras que nos unem - repensar la identidad: creencias, pais, color, clase, cultura. Barcelona: Taurus.

Biehl, J., Good, B. \& Kleinman, A. (eds). (2007). Subjectivity: ethnographic investigations. Berkeley, Los Angeles, London: University of California Press.

Butler, J. (2003). Problemas de gênero: feminismo e subversão da identidade. Rio de Janeiro: Civilização brasileira.

Cantelli, A. L. et. al. (2019). As Fronteiras da Educação: a realidade dxs estudantes Trans no Brasil. Curitiba: IBTE.

Csordas, T. (2013). "Fenomenologia cultural": corporeidade, agência, diferença sexual e doença. Educação, 36(3), 292-305. https://revistaseletronicas.pucrs.br/ojs/index.php/faced/article/ view/15523

Favret-Saada, J. (2005). “Ser Afetado”. Cadernos de Campo, 13, 155-161. https://doi.org/10.11606/ issn.2316-9133.v13i13p155-161

Hacking, I. (2002). Ontologia histórica. São Leopoldo: Unisinos.

Jesus, J. G. (2012). Orientações sobre a população transgênero: conceitos e termos. Brasília: Autor.

Lopes, G. L. (org.). (2001). O corpo educado: pedagogias da sexualidade. Belo Horizonte: Autêntica. 
Oliveira Junior, I. B. de \& Maio, E. R. (2016). Re/Des/Construindo In/diferenças: a expulsão compulsória de estudantes Trans do sistema escolar. Revista da FAEEBA - Educação e Contemporaneidade, 25(45), 159-172. https://revistas.uneb.br/index.php/faeeba/article/view/2292

Ortner, S. (2007). Subjetividade e Crítica cultural. Horizontes Antropológicos, 12(28), 375-405. http://dx.doi.org/10.1590/S0104-71832007000200015

Phillips, A. (2001). De uma política de ideias a uma política de presença? Revista Estudos Feministas, 9(1), 268-290. https://doi.org/10.1590/S0104-026X2001000100016

Ribeiro, D. (2019). Lugar de fala. São Paulo: Pólen.

Santos, S. P. \& Silva, E. P. de Q. (2017). O entrelaçamento entre transexualidade e educação escolar em dossiês de periódicos nacionais (1995-2016). InterMeio, 23(46), 39-61. https://periodicos.ufms. br/index.php/intm/article/view/5310

Souza, H. A. de \& Bernardo, M. H. (2014). "Transexualidade”: as consequências do preconceito escolar para a vida profissional. Bagoas: Estudos gays, gênero \& sexualidades, 8(11), 157-175. https:// periodicos.ufrn.br/bagoas/article/view/6548

Strathern, M. (2014). O gênero da dádiva: problemas com as mulheres eproblemas com a sociedade na melanésia. Campinas: Ed. UNICAMP. 


\title{
TRISTEZA, DISFORIA E BEM-ESTAR: PERSPECTIVAS ETNOGRÁFICAS SOBRE A ESCOLARIZAÇÃo DE PESSOAS TRANS
}

Resumo: A proposta deste artigo é atentar etnograficamente para as questões e demandas trazidas por estudantes Trans sobre seu processo de escolarização. A partir da minha experiência como docente voluntário no Coletivo pela Educação Popular, TransEnem, sediado em Porto Alegre (RS), tensiono a vivência escolar dos discentes Trans de modo a percebê-la como algo mais que apenas a passagem pela escola. Por meio de notas retiradas do meu diário de campo e depoimentos feitos durante a construção de oficinas de pesquisa com os/as discentes, constrói-se uma narrativa sobre os sentimentos, a corporeidade, os significados e as percepções que atravessam as potencialidades e vulnerabilidades do ser Trans nos espaços e tempos pedagógicos. $\mathrm{O}$ texto ainda problematiza aspectos referentes à subjetivação das identidades Trans e marca os processos políticos da aprendizagem dessas identidades frente aos diferentes espaços de socialização.

Palavras-chave: Etnografia; Escolarização; Pessoas Trans; Disforia.

\section{SADNESS, DYSPHORIA, AND WELL-BEING: ETHNOGRAPHIC PERSPECTIVES ON THE SCHOOLING OF TRANSGENDER PEOPLE}

\begin{abstract}
The purpose of this article is to pay ethnographic attention to the issues and demands brought by Transgender students about their schooling process. Based on my experience as a volunteer teacher at the Coletivo through Popular Education, TransEnem, based in Porto Alegre, Rio Grande do Sul State, Brazil, I tension the school experience of Trans students in order to perceive it as something more than just passage through school. Through notes taken from my field diary and statements made during the construction of research workshops with the students, a narrative is built about the feelings, the corporeality, the meanings, and the perceptions that cross the potentialities and vulnerabilities of being Trans in pedagogical spaces and times. The text also problematizes aspects related to the subjectivation of Trans identities and marks the political processes of learning these identities in front of different spaces of socialization.
\end{abstract}

Keywords: Ethnography; Schooling; Transgender People; Dysphoria.

RECEBIDO: $16 / 11 / 2019$

APROVADO: $11 / 01 / 2021$ 